David L. Andrews

Lasers in Chemistry 

David L. Andrews

\section{Lasers in Chemistry}

With 114 Figures and 3 Tables

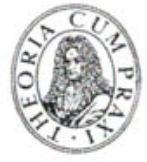

AKADEMIE-VERLAG BERLIN 1987 
Die Originalausgabe erscheint im Springer-Verlag

Berlin · Heidelberg $\cdot$ New York $\cdot$ London · Paris · Tokyo

Vertrieb ausschließlich für die DDR und die sozialistischen Länder Akademie-Verlag Berlin

Alle Rechte vorbehalten

(C) Springer-Verlag Berlin · Heidelberg 1985

ISBN 3-540-16 161-9 Springer-Verlag Berlin $\cdot$ Heidelberg $\cdot$ New York ISBN 0-387-16 161-9 Springer-Verlag New York · Heidelberg $\cdot$ Berlin

ISBN 3-05-500294-6 Akademie-Verlag Berlin

Erschienen im Akademie-Verlag Berlin, DDR - 1086 Berlin, Leipziger Straße 3-4

Lizenznummer: $202 \cdot 100 / 479 / 87$

Printed in the German Democratic Republic

Lichtsatz und Druck: INTERDRUCK Graphischer Großbetrieb Leipzig - III/18/97

Buchbinderische Weiterverarbeitung: VEB Druckhaus Köthen

LSV 1215

Bestellnummer: 7636540 (6979)

06800 
To my wife Karen

whose love and encouragement are inexpressibly precious 
